\title{
Heterofunctional Interfaces Achieve Dual Protein Adsorption on Polyelectrolyte Multilayers
}

\author{
By Heyun SHEN, ${ }^{1,2}$ Junji WATANABE, ${ }^{1,2}$ and Mitsuru AKASHI ${ }^{1,2, *}$
}

Two types of polyelectrolyte multilayers were formed on both sides of a substrate by integrating an alternate adsorption process with an alternate drop-coating process. We used poly(diallyldimethylammonium chloride) (PDDA) and poly(sodium 4-styrenesulfonate) (PSS) as strong polyelectrolytes. Each side of the substrate was covered with each polyelectrolyte, PDDA and PSS, then heterofunctional interfaces were obtained. Fluorescein isothiocyanate-labeled bovine serum albumin (FITCBSA) and cytochrome $c$ (cyt $c$ ) were used as model proteins for evaluating dual protein adsorption. The proteins FITC-BSA and cyt $c$ exhibited anionic and cationic charges, respectively, in tris(hydroxymethyl)aminomethane hydrochloride (Tris$\mathrm{HCl}$ ) buffer solution ( $\mathrm{pH}$ 7.4). From the results of protein adsorption from individual protein solutions, the FITC-BSA and cyt $c$ proteins were adsorbed on the outermost surfaces of PDDA and PSS, respectively. Moreover, dual protein adsorption was achieved in the case of a protein mixture. This result indicated that polyelectrolyte multilayers could easily control the surface charge to regulate protein adsorption from the protein mixture. In summary, a heterofunctional interface prepared from polyelectrolyte multilayers achieved dual protein adsorption on each side of a substrate from a protein mixture.

KEY WORDS: Heterofunctional Interface / Drop-Coating / Polyelectrolyte Multilayer / Dual Protein Adsorption /

Polyelectrolyte multilayers have been attracted extensive attention in various fields since they were first discovered by Decher in $1991 .^{1}$ Depending on the specific polymeric materials used in this process, the properties of an ultrathin film can be varied considerably and this process can be used to easily control the nanostructure of a substrate. ${ }^{2}$ Therefore, this process is useful for surface modification, which is extraordinarily advanced for biomedical application. ${ }^{3}$ In the conventional layer-by-layer (LbL) assembly process, synthetic and charged polymers (polyelectrolytes) are deposited on a substrate by alternate dip-coating. However, a recent study has shown that the LbL method is not restricted to charged materials and planar substrates in various fields. ${ }^{4}$ For instance, LbL assembly can be available on hydrogen bonding such as DNA hybridization and specific interaction for biomedical needs. Moreover, the LbL approach has an advantage that an LbL film can be readily transferred from planar to colloidal substrates. We have reported a number of LbL assemblies on various polymer combinations. For example, hollow capsules have been prepared via the LbL assembly of chitosan and dextran sulfate. ${ }^{5}$ Moreover, stereoregular polymerization was achieved by using the LbL assembly of isotactic (it) and syndiotactic (st) poly(methyl methacrylate) (PMMA) stereocomplex, ${ }^{6}$ and hollow capsules prepared from the stereocomplex were also achieved just by van der waals interactions. ${ }^{7}$ Taking this development into account, the LbL assemblies have good potential for high-performance device.

We have developed a novel alternate drop-coating process; that is an improvement over the conventional alternate adsorption process in that the novel process allows us to fabricate different polyelectrolyte multilayers on both sides of a substrate; the new process will thus facilitate the production of heterofunctional interfaces. ${ }^{8,9} \mathrm{We}$ have demonstrated that the multilayers produced by the novel drop-coating process was fairly similar to those obtained using the conventional dip-coating process in terms of the film thickness and the biofunction as a protein reservoir.

A number of studies have previously demonstrated that polyelectrolyte multilayers exhibit diverse functions with regard to protein adsorption. ${ }^{10-14}$ Schaaf et al. investigated the adsorption process between poly(styrenesulfonate)/poly(allylamine) (PSS/PAH) multilayers and series of positively and negatively charged proteins. ${ }^{10}$ Moreover, they have demonstrated that the secondary structure of adsorbed protein is changed by its electrostatic interaction with the polyelectrolyte multilayers. ${ }^{11}$ Müller et al. studied the effect of polyanion, $\mathrm{pH}$, and salt on protein adsorption on an $\mathrm{LbL}$ surface. ${ }^{12}$ On the other hand, Sukhishvili et al. investigated the alternate assembly of polyanion and positively charged protein in different $\mathrm{pH}$ and salt solution. ${ }^{13}$ Serizawa et al. demonstrated that dextran sulfate/chitosan multilayers can introduce anticoagulant or procoagulant properties which were dependent on the salt concentration and the number of steps of the assembly. ${ }^{14}$ From these reports, it is seen that polyelectrolyte multilayers have excellent potential for various biomedical applications that involve surface modification with the affinity or resistivity for proteins. Further, we conceive that heterofunctional interfaces can be prepared using polyelectrolyte multilayers.

In this study, we focus on the difference in protein adsorption on both sides of heterofunctional polyelectrolyte multilayers. Poly(diallyldimethylammonium chloride) (PDDA) 
Heterofunctional interfaces

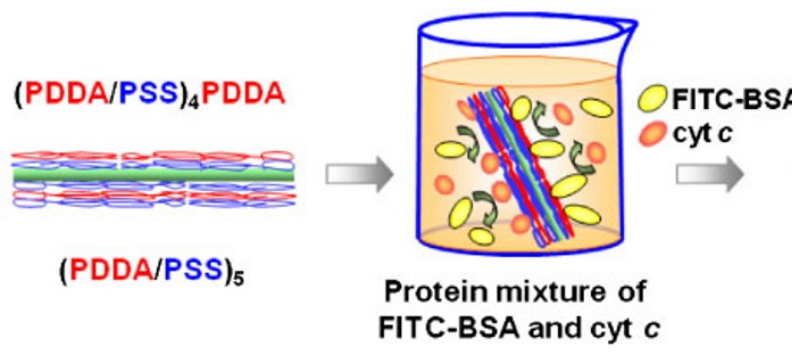

Dual protein adsorption

FITC-BSA on (PDDA/PSS) ${ }_{4}$ PDDA

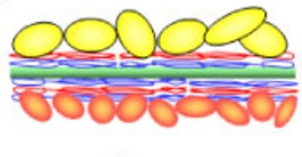

cyt $c$ on (PDDA/PSS) $)_{5}$

Figure 1. Illustration of dual protein adsorption on heterofunctional interfaces in this study.

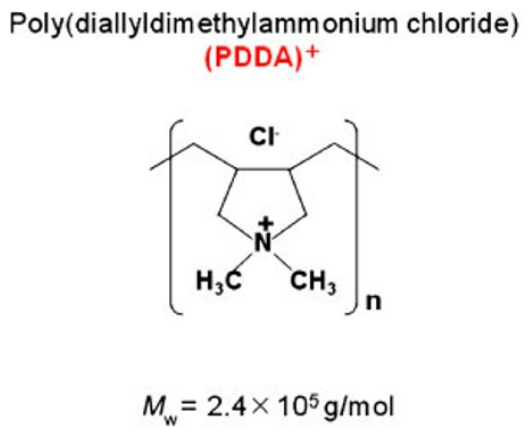

Poly(sodium 4-styrenesulfonate) (PSS) $^{-}$

Figure 2. Chemical structures of polyelectrolytes used in this study.

and poly(sodium 4-styrenesulfonate) (PSS) were selected as the polyelectrolytes. Many researchers have employed this polymer combination for fabricating polyelectrolyte multilayers. ${ }^{15-17}$ We integrated the alternate drop-coating process with the alternate dip-coating process for fabricating multilayers on both sides of a substrate: the outermost surface of a multilayer formed on one side of the substrate is cationic, while that of the multilayer formed on the other side of the substrate is anionic. (PDDA/PSS) ${ }_{4}$ PDDA (9-step assembly; outermost surface was PDDA) was first assembled on both sides of the substrate by alternate dip-coating; then, a droplet of PSS solution was placed on one side of the substrate in order to deposit a PSS layer by drop-coating. Therefore, PDDA and PSS were situated on the opposite outermost surfaces of the substrate. Fluorescein isothiocyanate-labeled bovine serum albumin (FITC-BSA) and cytochrome $c$ (cyt $c$ ) were used as model protein adsorbates. The isoelectric points (pI) of FITC-BSA and cyt $c$ are roughly 4.9 (as BSA) and 10.2, respectively. Therefore, these two proteins exhibited anionic and cationic charges in a tris(hydroxymethyl)aminomethane hydrochloride (Tris-HCl) buffer solution ( $\mathrm{pH} 7.4$ ), respectively. Further, the FITC-BSA and cyt $c$ proteins were adsorbed on the outermost surfaces of PDDA and PSS, respectively. Electrostatic force was the major interaction in this process. Moreover, the protein adsorption was carried out using a protein mixture. The heterofunctional polyelectrolyte multilayers induced dual protein adsorption on both side of the substrate in the case of this protein mixture [Figure 1]. Protein separation of a binary protein mixture by oppositely charged polymers has been studied under different solution $\mathrm{pH}^{18-20}$ Wang et al. demonstrated that multi-wall carbon nanotubes (MWNTs) $/ \mathrm{SiO}_{2}$-packed micro-column can effectively separate cyt $c$ from BSA solution by electrostatic interaction between MWNTs and the protein. ${ }^{21}$ In the present study, we demonstrated that polyelectrolyte multilayers also can easily control the surface charge in order to regulate protein adsorption from a mixture. Moreover, this is the first challenge to simultaneously dual protein adsorption on each side of a substrate that is covered with polyelectrolyte multilayers. Thus, using alternate drop-coating, we can fabricate heterofunctional interface, thereby achieving heterobiofunction on both sides of a substrate along with dual protein adsorption from a protein mixture.

\section{EXPERIMENTAL}

\section{Materials}

The polyelectrolytes used in this study are shown in Figure 2. Poly(diallyldimethylammonium chloride) (PDDA, $\# 17338$; Polyscience Inc., PA, USA; $M_{\mathrm{w}}=2.4 \times 10^{5} \mathrm{~g} / \mathrm{mol}$ ) and poly(sodium 4-styrenesulfonate) (PSS, \#561959; Aldrich, MO, USA; $M_{\mathrm{w}}=2.0 \times 10^{5} \mathrm{~g} / \mathrm{mol}$ ) were used as strong polyelectrolytes. Fluorescein isothiocyanate-labeled albumin (FITC-BSA, A9771) and cytochrome $c$, from bovine heart (cyt $c$, C2037) were purchased from SIGMA, MO, USA. Seven to twelve FITC molecules have labeled on a BSA molecule. Tris(hydroxymethyl)aminomethane hydrochloride (Tris-HCl; Wako Pure Chemical Industries, Ltd., Osaka, Japan) was used as a buffer solution. All chemicals were used without further purification. Ultrapure water was used throughout the experiment. 


\section{Fabrication of LbL Assembly on a Quartz Plate}

The polyelectrolyte solutions-PDDA and PSS-were separately dissolved in $50 \mathrm{mmol} / \mathrm{L}$ Tris- $\mathrm{HCl}(\mathrm{pH} \mathrm{7.4})$, and the concentration of each solution was adjusted to $0.2 \mathrm{mg} / \mathrm{mL}$. Then, the ionic strength of each solution was adjusted to $0.15 \mathrm{~mol} / \mathrm{L}$ using $\mathrm{NaCl}$. Before performing alternate adsorption, both sides of a quartz plate $(40 \times 9 \times 1 \mathrm{~mm})$ were treated with a piranha solution (concentrated $\mathrm{H}_{2} \mathrm{SO}_{4} / \mathrm{H}_{2} \mathrm{O}_{2}$ (30 wt \% aqueous solution) $=3 / 1, \mathrm{v} / \mathrm{v}$ ) for $1 \mathrm{~min}$; subsequently, the plate was rinsed with ultrapure water. This treatment was repeated twice. Subsequently, the plate was dried with $\mathrm{N}_{2}$ gas and used for the alternate adsorption process.

First, we briefly describe the conventional alternate adsorption on a quartz plate. The quartz plate was first immersed in a PDDA aqueous solution for $1 \mathrm{~min}$ at room temperature and then its UV-vis spectrum was recorded (light path $=1 \mathrm{~mm}$ ) without any buffer solution by U3010 spectrometer (Hitachi, Tokyo, Japan). Here, it is worth mentioning that originally, the UV-vis method was utilized for the evaluation of the proteins adsorbed on a quartz plate. ${ }^{22} \mathrm{Next}$, the quartz plate was immersed in a PSS aqueous solution and then its UV-vis spectrum was recorded as described above. The alternate adsorption process was repeated for the preparation of polyelectrolyte multilayers. The resulting LbL assemblies were identified from the change in absorbance as a function of the number of PSS layers. To estimate total PSS deposition, the quartz plate was positioned vertically in a quartz cuvette containing $50 \mathrm{mmol} / \mathrm{L}$ of Tris- $\mathrm{HCl}(\mathrm{pH} \mathrm{7.4)}$, and its $\mathrm{UV}$-vis absorbance at $225 \mathrm{~nm}$ (light path $=10 \mathrm{~mm}$ ) was measured. From this measured absorbance, the amount of PSS deposition during the LbL assembly was estimated using a standard absorbance curve of PSS solutions. Ishihara et al. reported that the standard curves of protein solutions were used to determine the amount of proteins adsorption on a substrate. ${ }^{22}$ In their report, the amount of protein molecules adsorbed on the quartz plate was equivalent to that in the protein solution in the total light path. The PSS amount estimated from the absorbance plate was compared with the results of a quartz-crystal microbalance (QCM) analysis. The QCM protocol was reported in our previous study. ${ }^{8}$

In the present study, we integrated the alternate dip-coating and alternate drop-coating processes for the fabrication of two types of outermost surfaces on both sides of the substrate for which the surface charges used were cationic and anionic, respectively. (PDDA/PSS) ${ }_{4}$ PDDA was first assembled on both sides of the substrate using the abovementioned alternate dipcoating process. Subsequently, a droplet of PSS solution (approximately $1 \mathrm{~mL}$ ) was placed on one side of the substrate for $1 \mathrm{~min}$ at room temperature in order to deposit the PSS layer (PDDA/PSS $)_{5}$. Therefore, PDDA and PSS were situated on the opposite outermost surfaces of the substrate.

\section{Characterization of Adsorbed Protein on Polyelectrolyte Multilayers}

FITC-BSA and cyt $c$ were used as proteins in order to evaluate dual protein adsorption. Seven to twelve FITC molecules have labeled on a BSA molecule (pI 4.9) and FITC molecule was anionic in the buffer solution ( $\mathrm{pH}$ 7.4). Therefore, in a Tris- $\mathrm{HCl}$ buffer solution ( $\mathrm{pH} 7.4)$, FITC-BSA and cyt $c$ (pI 10.2) exhibited anionic and cationic charges, respectively. $(\mathrm{PDDA} / \mathrm{PSS})_{4} \mathrm{PDDA}$ and (PDDA/PSS) $)_{5}$ were assembled on quartz plates by alternate dip-coating; each plate was then separately incubated in FITC-BSA $[0.45 \mathrm{mg} / \mathrm{mL}(6.8 \mu \mathrm{mol} / \mathrm{L})$; Tris-HCl, $50 \mathrm{mmol} / \mathrm{L} ; \mathrm{pH} 7.4]$ and cyt $c[0.45 \mathrm{mg} / \mathrm{mL}(35$ $\mu \mathrm{mol} / \mathrm{L})$; Tris-HCl, $50 \mathrm{mmol} / \mathrm{L} ; \mathrm{pH} 7.4]$ solution for $1 \mathrm{~h}$ at $37^{\circ} \mathrm{C}$. Thereafter, the plate was rinsed with $1 \mathrm{mmol} / \mathrm{L}$ Tris- $\mathrm{HCl}$ buffer solution, and the amounts of FITC-BSA and cyt $c$ adsorption were estimated from the UV-vis absorbance at $494 \mathrm{~nm}$ and $410 \mathrm{~nm}$, respectively, using a standard absorbance curve of each protein solution.

In order to study dual protein adsorption, a protein mixture was prepared by mixing FITC-BSA and cyt $c(1: 1, \mathrm{v} / \mathrm{v})$ solutions. The concentration of each protein solution was the same as earlier, namely, $0.45 \mathrm{mg} / \mathrm{mL}$. The protein adsorption was carried out for $1 \mathrm{~h}$ at $37^{\circ} \mathrm{C}$. The amounts of adsorbed FITC-BSA and cyt $c$ were simultaneously estimated from the UV-vis absorbance at $494 \mathrm{~nm}$ and $410 \mathrm{~nm}$, respectively, using the standard curve of each protein solution.

\section{RESULTS AND DISCUSSION}

\section{Evaluation of LbL Assembly on a Quartz Plate}

We have previously evaluated the PDDA/PSS assembly on a QCM substrate by stepwise frequency shift due to the change in mass. ${ }^{8}$ Moreover, the resulting assemblies produced by the alternate drop-coating process were very similar in quality to those obtained by the conventional alternate dip-coating for the fabrication of the LbL assembly. ${ }^{9}$ However, a QCM instrument measures only the change in the mass of a substrate. Consequently, if a protein mixture is used, it is difficult to identify the individual proteins. Therefore, in order to demonstrate dual protein adsorption, we employed a quartz plate to fabricate heterofunctional polyelectrolyte multilayers.

Figure 3(a) shows the UV-vis spectra of the stepwise assembly of PDDA/PSS on a quartz plate. (PDDA/ PSS $)_{4}$ PDDA (9-step) was also investigated. The absorbance at $225 \mathrm{~nm}$ corresponding to the aromatic chromophore in the styrene unit of the PSS layer steadily increased with the number of PSS layers. The absorbance did not change in the case of PDDA deposition. Decher et al. demonstrated the absorbance increases regularly with the number of PSS layers from of PSS/PAH assembly. ${ }^{23}$ After the deposition of each layer during the (PDDA/PSS) ${ }_{4}$ PDDA assembly process, the absorbance at $225 \mathrm{~nm}$ was recorded and the plots are shown in Figure 3(a). The blue plots (even steps) indicate PSS layer deposition. A numerical fit (dotted line) to these data revealed that the change in absorbance per layer was exponential. This relationship was similar to that specified in the QCM protocol. On the basis of this observation, it appears that the polyelectrolyte multilayers were properly assembled on the quartz plate. 

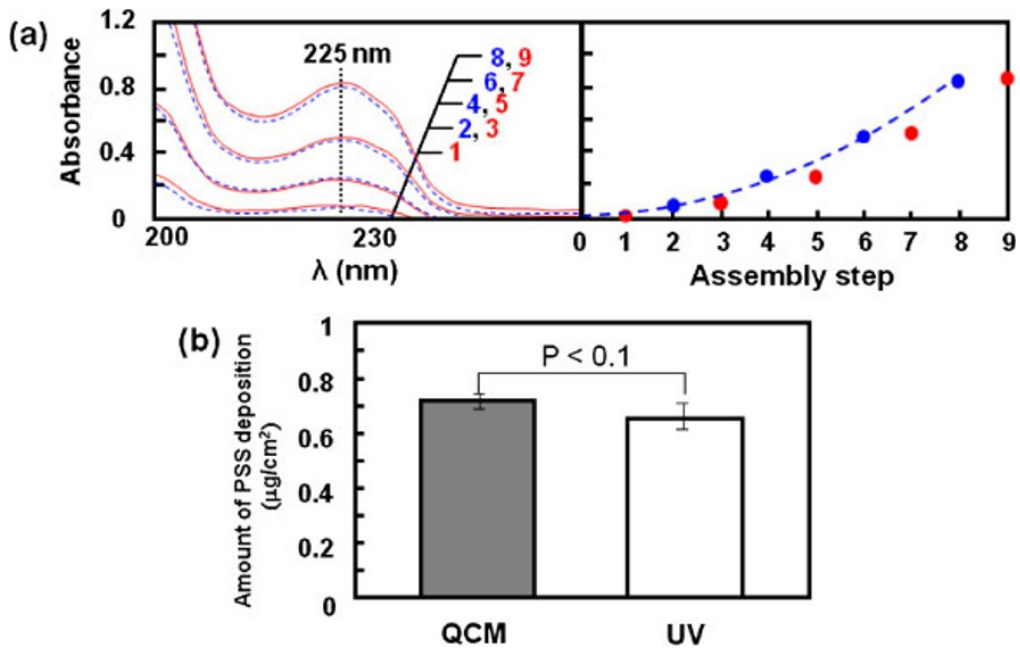

Figure 3. (a) UV-vis spectra obtained by stepwise assembly of PDDA (red, solid line) and PSS (blue, dotted line) on a quartz plate (left), and UV absorbance at $225 \mathrm{~nm}$ obtained by stepwise assembly of PDDA (red, odd steps) and PSS (blue, even steps) (right). (b) Amount of PSS deposition on (PDDA/ PSS $)_{4}$ PDDA, evaluated by UV spectra and QCM protocols $(n=2)$.

We also determined the amount of PSS deposition during the (PDDA/PSS $)_{4}$ PDDA assembly on the quartz plate. This result was compared with the QCM result [Figure $3 \mathrm{~b}$ ]. The amount of PSS deposition during the (PDDA/PSS) ${ }_{4}$ PDDA assembly was calculated from the frequency shift. The PSS amounts determined from QCM analysis and UV spectroscopy were approximately $0.72 \mu \mathrm{g} / \mathrm{cm}^{2}$ and $0.65 \mu \mathrm{g} / \mathrm{cm}^{2}$, respectively. Figure 3(b) shows a slight difference between the two abovementioned methods. The use of a different substrate (including different surface morphologies and hydrophilicity) probably caused the slight difference in the amount of polyelectrolyte deposition in the LbL assembly. However, the reproducibility was good in the case of UV spectroscopy. This result indicated that $\mathrm{LbL}$ ultrathin films are also precisely characterized by UV spectroscopy. The LbL assembly was prepared by the conventional dip-coating process. In our previous report, the drop-coating method was demonstrated to be similar to the dip-coating process $;^{8}$ therefore, in the present study, the LbL assembly prepared by drop-coating was not characterized by UV spectroscopy.

\section{Heterofunctional Interfaces Achieve Dual Adsorption from a Protein Mixture}

We have demonstrated that the heterofunctional interfaces could regulate the amount of protein adsorption on each side of the substrate and hence can be used to fabricate a heterofunctional biointerface. ${ }^{9}$ Moreover, these multilayers could function as protein or biomolecule reservoirs on both sides of the substrate. Therefore, these multilayers could serve as an ideal heterofunctional biointerface and permit varied optimization for biomedical applications.

FITC-BSA and cyt $c$ were used as model proteins in order to evaluate dual protein adsorption. In Tris- $\mathrm{HCl}$ buffer solution ( $\mathrm{pH} 7.4$ ), these two proteins exhibited anionic and cationic charges, respectively. In general, multilayers bearing a particular surface charge adsorb oppositely charged biomolecules.

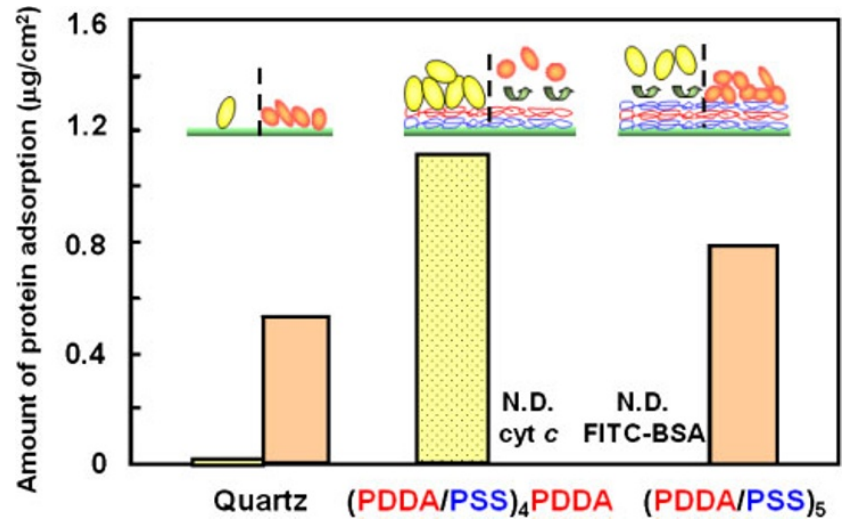

Figure 4. Amount of FITC-BSA and cyt $c$ adsorption on quartz plate, (PDDA/PSS) ${ }_{4}$ PDDA, and (PDDA/PSS) $)_{5}$. Yellow (dot) and orange bars indicate FITC-BSA and cyt $c$, respectively.

Moreover, the adsorption of charged proteins occurs to a considerably lower extent when driven by nonelectrostatic forces. ${ }^{15}$ We have assumed that electrostatic interaction also regulates protein adsorption. Therefore, we assume that the two model proteins FITC-BSA and cyt $c$ were specifically adsorbed on $(\mathrm{PDDA} / \mathrm{PSS})_{4} \mathrm{PDDA}$ and $(\mathrm{PDDA} / \mathrm{PSS})_{5}$, respectively. Figure 4 shows FITC-BSA and cyt $c$ adsorbed on various substrates. From the result shown, $1.12 \mu \mathrm{g} / \mathrm{cm}^{2}$ of FITC-BSA and $0.79 \mu \mathrm{g} / \mathrm{cm}^{2}$ of cyt $c$ were adsorbed on (PDDA/ PSS $)_{4}$ PDDA and $(\mathrm{PDDA} / \mathrm{PSS})_{5}$, respectively. Moreover, the adsorbed amounts of both proteins were higher than those adsorbed on a quartz plate used as the control (FITC-BSA: $0.01 \mu \mathrm{g} / \mathrm{cm}^{2}$, cyt $c: 0.53 \mu \mathrm{g} / \mathrm{cm}^{2}$ ). However, cyt $c$ and FITCBSA were not detected on (PDDA/PSS) $)_{4} \mathrm{PDDA}$ and (PDDA/ $\mathrm{PSS})_{5}$, respectively. This result indicates that the fabricated polyelectrolyte multilayer has an excellent potential for dual protein adsorption. An oppositely charged protein could adsorb on a multilayer. On the other hand, the multilayer prevented the adsorption of protein bearing the same type of charge as that of 

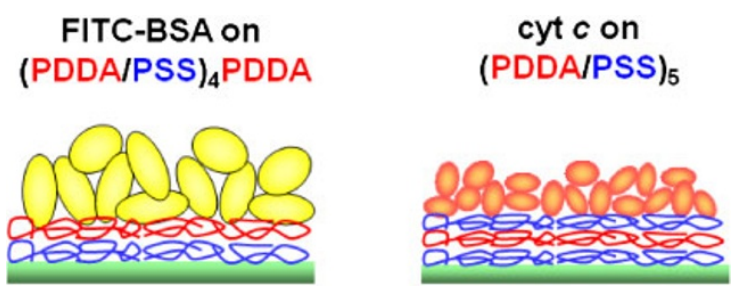

Figure 5. Schematic illustrations of FITC-BSA and cyt $c$ adsorption on (PDDA/PSS) ${ }_{4}$ PDDA and (PDDA/PSS $)_{5}$, respectively.

the outermost surface of the multilayer in this time which the ionic strength of the protein solution was approximately zero. The electrostatic interaction, electrostatic attraction and electrostatic repulsion between multilayers and the protein, are considered to be assumably weaken and/or dissipation in high ionic strength of the protein solution. ${ }^{8}$

The concentration of FITC-BSA and cyt $c$ solution were $0.45 \mathrm{mg} / \mathrm{mL} \quad(6.8 \mu \mathrm{mol} / \mathrm{L})$ and $0.45 \mathrm{mg} / \mathrm{mL} \quad(35 \mu \mathrm{mol} / \mathrm{L})$, respectively. The sizes of FITC-BSA and cyt $c$ are approximately $14 \times 4 \times 4 \mathrm{~nm}^{3}$ and $3.7 \times 2.5 \times 2.5 \mathrm{~nm}^{3}$, respectively. ${ }^{24}$ From the molecular weights of these proteins (FITC$\mathrm{BSA}=66 \mathrm{kDa}$, cyt $c=13 \mathrm{kDa}$ ), we have calculated the amounts of FITC-BSA and cyt $c$ bound to the respective surfaces as $0.9 \mu \mathrm{g} / \mathrm{cm}^{2}$ and $0.45 \mu \mathrm{g} / \mathrm{cm}^{2}$, respectively. These values were calculated assuming that the protein adsorbed on the surface formed a monolayer in "end-on" position. Therefore, the coverage of FITC-BSA on (PDDA/PSS) $)_{4}$ PDDA and cyt $c$ on (PDDA/PSS) $)_{5}$ were $124 \%$ and $175 \%$, respectively. On the other hand, the thicknesses of (PDDA/PSS) $)_{4}$ PDDA and $(\text { PDDA/PSS })_{5}$ were approximately $12.3 \mathrm{~nm}$ and $14.8 \mathrm{~nm}$, respectively, which were slightly lager than each protein size. Moreover, the roughness of resulting multilayers should be low. Therefore, we speculate that the most of proteins were adsorbed on the multilayers surface with bilayer (Figure 5), and no protein penetration and monolayer adsorption on each polyelectrolyte multilayers as result of low roughness of the multilayers.

On the basis of above results, we considered that from the protein mixture, competitive protein adsorption on the polyelectrolyte multilayers resulted from the electrostatic interaction between a multilayer surface and the protein adsorbed on that surface. Moreover, the competitive adsorption behavior would be different on each side of the heterofunctional interfaces and it contributes to the function of these multilayers as a reservoir of diverse proteins. First of all, we tested the protein mixture; in particular, whether the electrostatic interaction between FITC-BSA and cyt $c$ was high or not. From the UV-vis spectra of the proteins shown, the specific peaks of FITC-BSA and cyt $c$ of the protein mixture were observed in a spectrum. Long et al. reported a change in the UV absorbance of BSA due to aggregation. ${ }^{25}$ This result indicated that FITC-BSA and cyt $c$ could not aggregate in the mixture by electrostatic interaction. Therefore, the mixture of FITC-BSA and cyt $c$ was available for dual protein adsorption.

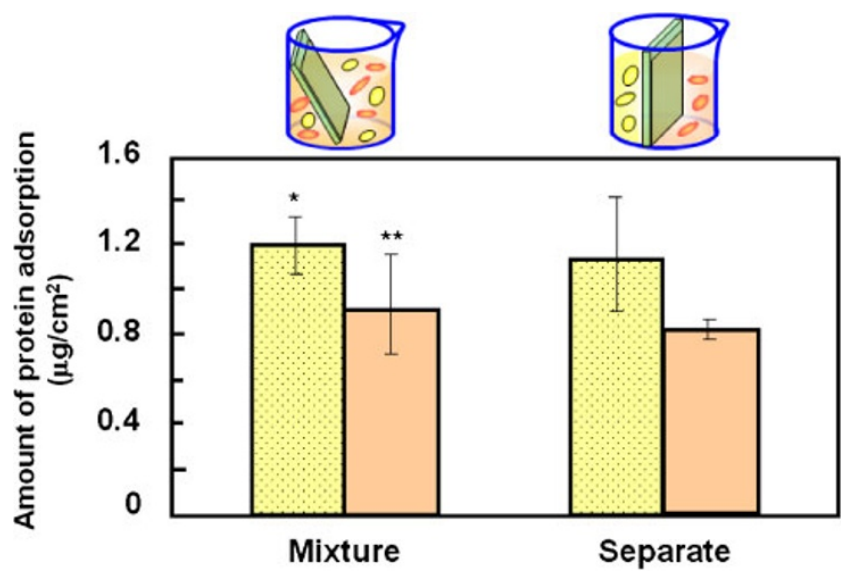

Figure 6. Dual protein adsorption on the substrate, from protein mixture (left) and separate protein solutions (right). Yellow (dot) and orange bars indicate FITC-BSA and cyt $c$, respectively. $(\mathrm{n}=2){ }^{*},{ }^{* *}$ : The amounts of protein adsorption from protein mixture were not significantly different from those adsorption from separate protein solutions.

We integrated the drop-coating with dip-coating processes for the preparation of polyelectrolyte multilayers. Moreover, the protein adsorption behavior was similar irrespective of the use of a protein mixture or individual protein solutions (Figure 6). In the case of individual protein adsorption, FITCBSA and cyt $c$ proteins were directly adsorbed on each side of a substrate, that were covered by (PDDA/PSS) $)_{4}$ PDDA and $(\mathrm{PDDA} / \mathrm{PSS})_{5}$ multilayers, respectively. The protein adsorption was carried out using a quartz cuvette, which was divided into two parts by the resulting heterofunctional substrate described above. As shown in Figure $6,1.21 \mu \mathrm{g} / \mathrm{cm}^{2}$ of FITCBSA and $0.91 \mu \mathrm{g} / \mathrm{cm}^{2}$ of cyt $c$ were adsorbed from the protein mixture, and $1.15 \mu \mathrm{g} / \mathrm{cm}^{2}$ of FITC-BSA and $0.82 \mu \mathrm{g} / \mathrm{cm}^{2}$ of cyt $c$ were adsorbed from the individual protein solutions. Moreover, the amounts of protein adsorption from the protein mixture were not significantly different from those adsorbed from individual protein solutions. From this result shown, we can speculate that the polyelectrolyte multilayers could easily control the surface charge in order to regulate protein adsorption from a protein mixture.

Moreover, we tested sequential protein adsorption and the protein adsorption from the protein mixture on individual polyelectrolyte multilayers, in order to demonstrate dual protein adsorption from the protein mixture. The adsorbed amount of each protein in sequential protein adsorption was less than that adsorbed on a quartz plate in each case (Figure 7). This result indicated that sequential protein adsorption is independent of the electrostatic interaction with the first adsorbed protein. Therefore, it was considered that in sequential protein adsorption, hydrophilicity of the outermost surface was the dominant factor and did not allow the sequential adsorption of the two different types of proteins. The charge at the outermost surface of a multilayer might be reduced by protein adsorption. From the result, the protein adsorption from the protein mixture on individual polyelectrolyte multilayers indicated that FITC-BSA and cyt $c$ 


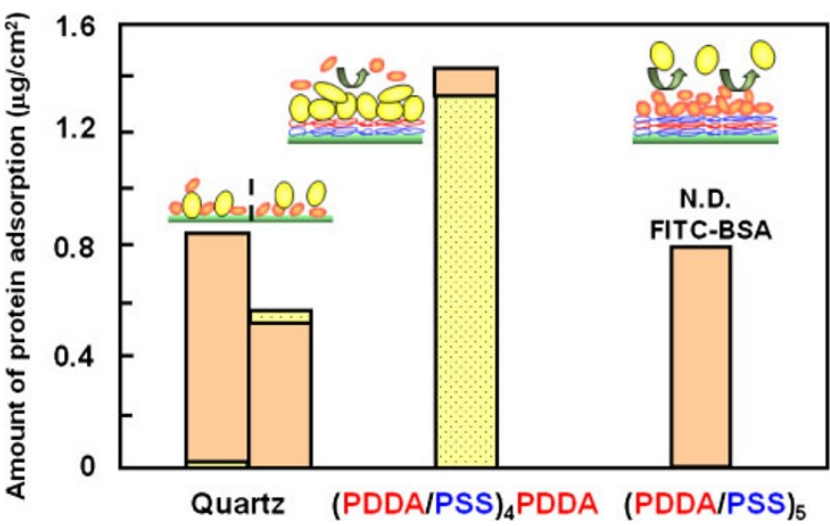

Figure 7. Sequential protein adsorption on the substrate. Yellow (dot) and orange bars indicate FITC-BSA and cyt $c$, respectively.

molecules were competitively adsorbed on (PDDA/PSS $)_{4}$ PDDA and (PDDA/PSS) 5 , respectively. The competitive adsorption was considered to be via electrostatic interaction. Above result strongly suggested that polyelectrolyte multilayers can be featly regulate the surface charge to achieve dual adsorption from a protein mixture. Therefore, the heterofuctional interfaces prepared from polyelectrolyte multilayers can be easily achieved dual protein adsorption on the each side of a substrate from a protein mixture.

\section{CONCLUSIONS}

The heterofunctional interfaces were prepared by integrating the alternate drop-coating with dip-coating processes. Moreover, the heterofunctional multilayers induced dual protein adsorption from a protein mixture. We suggest that these novel heterofunctional biointerfaces could contribute to be forming an excellent spacer connecting different functional interfaces.

Acknowledgment. The authors thank Drs. T. Kida, M. Matsusaki, H. Ajiro, and T. Akagi from Osaka University for their helpful discussions. A part of this study was financially supported by a Grant-in-Aid for the 21st Century COE Program "Center for Integrated Cell and Tissue Regulation (CICET)" from The Ministry of Education, Culture, Sport, Science and Technology, Japan. One of the authors (H. Y. S.) was supported by a grant from CICET and a scholarship from Osaka Foundation of International Exchange.
Received: January 26, 2009

Accepted: February 24, 2009

Published: April 15, 2009

\section{REFERENCES}

1. G. Decher and J. D. Hong, Macromol. Chem., Macromol. Symp., 46, 321 (1991).

2. G. Decher, Science, 277, 1232 (1997).

3. Z. Y. Tang, Y. Wang, P. Podsiadlo, and N. A. Kotov, Adv. Mater., 18, 3203 (2006).

4. J. F. Quinn, A. P. R. Johnston, G. K. Such, A. N. Zelikin, and F. Caruso, Chem. Soc. Rev., 36, 707 (2007).

5. Y. Itoh, M. Matsusaki, T. Kida, and M. Akashi, Biomacromolecules, 7, 2715 (2006).

6. T. Serizawa, K.-I. Hamada, and M. Akashi, Nature, 429, 52 (2004).

7. T. Kida, M. Mouri, and M. Akashi, Angew. Chem., Int. Ed., 45, 7534 (2006).

8. J. Watanabe, H. Y. Shen, and M. Akashi, Acta Biomater., 4, 1255 (2008).

9. J. Watanabe, H. Y. Shen, and M. Akashi, J. Mater. Sci. Mater. Med., 20, 759 (2009).

10. G. Ladam, P. Schaaf, G. Decher, J. C. Voegel, and F. J. G. Cuisinier, Biomol. Eng., 19, 273 (2002).

11. P. Schwinté, V. Ball, B. Szalontai, Y. Haikel, J. C. Voegel, and P. Schaaf, Biomacromolecules, 3, 1135 (2002).

12. M. Müller, T. Rieser, P. Dubin, and K. Lunkwitz, Macromol. Rapid Commun., 22, 390 (2001).

13. V. A. Izumrudov, E. Kharlampieva, and S. A. Sukhishvili, Biomacromolecules, 6, 1782 (2005).

14. T. Serizawa, M. Yamaguchi, and M. Akashi, Biomacromolecules, 3, 724 (2002).

15. D. S. Salloum and J. B. Schlenoff, Biomacromolecules, 5, 1089 (2004).

16. H. Y. Liu and N. F. Hu, J. Phys. Chem. B, 109, 10464 (2005).

17. X. Roy, P. Sarazin, and B. D. Favis, Adv. Mater., 18, 1015 (2006).

18. A. Saxena and V. K. Shahi, J. Membr. Sci., 299, 211 (2007).

19. X. Zhang, R. B. Bai, and Y. W. Tong, Sep. Purif. Technol., 52, 161 (2006).

20. J. Y. Yoon, J. H. Lee, J. H. Kim, and W. S. Kim, Colloids Surf., B, 10, 365 (1998).

21. Z. Du, Y. L. Yu, X. R. Yan, and J. H. Wang, Analyst, 133, 1373 (2008).

22. K. Ishihara, H. Nomura, T. Mihara, K. Kurita, Y. Iwasaki, and N. Nakabayashi, J. Biomed. Mater. Res., 39, 323 (1998).

23. G. Decher, in "Multilayer Thin Fimls," G. Decher and J. B. Schlenoff, Ed., WILEY-VCH Verlag GmbH \& Co. KGaA, Weinheim, 2003, Chap. 1, p 7.

24. W. R. Glomm, Ø. H. Jr, A. D. Hanneseth, and S. Volden, J. Phys. Chem. B, 111, 14329 (2007).

25. X. Long, C. Zhang, J. Cheng, and S. Bi, Spectrochim. Acta, Part A, 69. 71 (2008). 